\title{
Factors Influencing the Intentions to Adopt Technology of the Broiler Farmer in Livestock Region 3, Thailand
}

\author{
Apisara Wichean and Mullika Sungsanit* \\ School of Management Technology, Suranaree University of Technology, \\ Nakhon Ratchasima 30000, Thailand
}

('Corresponding author's e-mail: mullika@g.sut.ac.th)

Received: 8 September 2020, Revised: 24 April 2021, Accepted: 8 May 2021

\begin{abstract}
This research aimed to study the types and influence of mindsets, performance expectancy, effort expectancy, social influence and facilitating conditions on farmers' intention to adopt a technology. The research participants were 110 broiler farmers in livestock region 3 . The research used a questionnaire to collect quantitative data and analyse the data using frequency, percentage, mean, standard deviation, correlation coefficient and structural equation modeling with maximum likelihood estimation to analyse path coefficienct and structural relationships. The result showed that most of the participants have a growth mindset more than a fixed mindset. Performance expectancy, effort expectancy, social influence and facilitating conditions have directly affected boiler farmers' intention to adopt the technology. Effort expectancy has a total effect on attitude toward using technology. Interestingly, facilitating conditions have shown the most considerable influence on attitude toward adopting the technology. Mindsets have an influence on effort expectancy and facilitating conditions.
\end{abstract}

Keywords: Mindsets, Growth mindset, Technology adoption, Poultry farm management system, Smart farm

\section{Introduction}

Internet of Things (IoT) is a technology that can connect physical objects to the internet. Experts expect the IoT to be one of the key drivers that will support intelligent agriculture in Thailand since IoT allows humans to collect data that support the digital transformation [1]. The digital transition is vital for businesses due to the current era of digital darwinism [2], an era in which technology is developed faster than traditional businesses can adapt. As a result, existing businesses are at risk of losing competitiveness [3]. According to McKinsey \& Company's ranking of digital industry transformation processes, the agricultural industry is at a high risk of being replaced [4].

In 2016, the frozen and processed chicken industry in Thailand was ranked $9^{\text {th }}$ globally, with exports continuing to grow. After Thailand has been free from the bird flu outbreak for almost 10 years, consumers have confidence in Thailand's poultry products [5]. Thai broiler farmers will be at risk in production. The problem of inclement weather, which causes the low survival rate of the product and the increase in production costs, affects the ability to compete because the world's major exporting countries, such as Brazil and the United States, have cheaper production costs. From having more modern production, technology is replacing human labour and large production [6].

Production risks associated with Thai broiler farmers have resulted from the lack of information to support farmers' decisions to manage production processes, especially atmospheric information. Small and medium-sized broiler farmers do not invest in this technology. Therefore, Farmz Master TM, a new agricultural technology entrepreneur, has developed a poultry farm management system using IoT to collect climate data in the house and report its atmospheric conditions inside the building. The expectation is for farmers to use this information to make decisions in managing poultry farms. However, introducing technology to farmers is challenging because of farmers' resistance to investing in products or services they cannot use [7]. If farmers' resistance is the key to introducing new technology, why would some farmers be more apt to adopt new technology to their farms? Are farmers so fixed and afraid of adopting new things? What are they looking for if they would adopt new technology? To introduce new technology that can help farmers be more competent and able to compete, understanding the farmers' 
attitude and thinking would help entrepreneurs and agricultural supporters deal and successfully introduce new technology to farmers.

Technology adoption is about the use or acceptance of new technology or new product. To understand technology adoption is to understand human attitude and behaviour. Human behaviour is the result of behavioural intention. According to the theory of planned behaviour (TPB), factors that influence the intention to act include the attitude towards behaviour, people's norms around the behaviour (subjective norm) and perceived behavioural control [8]. Though the TPB has been widely used in studying people behavioural intention, it is not adequate to use to study technology adoption intention since it is more complex and has the newness and fear dimension in the adoption. Recently, the Unified Theory of Acceptance and Use of Technology (UTAUT) is often used as the theoretical basis in studying technology adoption in many technologies and industries.

UTAUT describes the factors that directly influence the use of technology: intention behaviour and facilitating conditions. UTAUT framework suggests that performance expectancy, effort expectancy and social influence will influence behavioural intentions [9]. A recent study of technology adoption among farmers found that direct factors affecting weather information technology adoption for wheat growers are attitudes towards behaviour and intention [10]. Attitude is the most influential factor in adopting climate forecasts technology, followed by the norm, agricultural income and perceived behaviour control [11]. [12] found that attitude, social norm and perceived behavioural control had an influence on the intention to use ICTs for agricultural risk management in Malaysia. [13] found that participants' belief that precision agriculture technology would improve environmental quality is the main reason for adopting precision agriculture technology in American cotton production. [14] found that gender, agricultural income, understanding of new technology, perceived ease of use and perceived usefulness influence unmanned aerial vehicles technology adoption.

Various studies have shown that many factors influence technology usage behaviour. [15] found that the adoption of water purification systems influenced by the intention to use and facilitating conditions. Intention to use water purification systems influenced by performance expectancy, effort expectancy, physical support and education support. [16] found that farmers' willingness to demonstrate behaviour and facilities directly influenced the adoption of farmers' crop protection applications. Moreover, the determination of behaviour is influenced by performance expectations in an effort and social influence. [17] found that intention and facilitating conditions influence the use of pressurised irrigation technology. Performance expectancy and social influence intention to use pressurised irrigation technology. Nevertheless, effort expectancy had no significant relationship with behavioural intention to adopt pressurised irrigation technology. Performance expectancy and facilitating conditions influence farmers' intention to adopt agricultural apps, but effort expectancy and social influence had no significant relationship with behavioural intention to adopt agricultural apps [18]. Facilitating conditions, performance expectancy and effort expectancy influence mobile applications used by farmers for data and information management. However, the relationship between social influence and mobile applications is negative [19].

Digital solutions are becoming vital since it allows a business to run at market speed and critical elements of a market speed. An organisation needs to be flexible, scalable, adopt a culture-led approach with new ways of working, break down barriers and drive toward common goals [20]. A growth mindset is expected as a key to digital transformation [21]. [22] found that a growth mindset is good for the organisation since it will impact behaviour change at scale, increase employee engagement, and increase workplace satisfaction. [23] proposed that people with different mindsets will have different behaviour expressions. Mindset is described by the belief that human beings and their characteristics, such as intelligence and personality. When faced with a circumstance, humans have different evaluations and expressions toward the situation. There are 2 types of mindset, i.e., growth and fixed mindset [24]. People who have different mindsets will have different expectations and goals in life and activities. People with fixed mindsets will put importance on efficiency and productivity. On the other hand, people with growth mindsets will emphasise learning, effort, improvement and adaptability [25]. [26] studied the relationship between mindsets and mobile technology acceptance for learning and found that the teachers with the growth mindsets tended to accept mobile technology for classroom teaching. [27] found that teachers with a growth mindset also exhibited the diligently developing themselves for their career growth. They would continuously look for new things and bring them into use in their teaching.

Theories and previous studies have indicated that attitudes, intention, environmental factors and mindset influence human behaviour. Mindset, growth vs fixed, is increasingly getting both academia's and practitioners' attention. Recently academia has just started to pay attention to the relationship between mindset and technology adoption. However, there have not found any study that focuses on understanding 
the relationship between mindset and technology adoption in the agriculture industry. Hence, some questions need answers. What is the type of mindset that boiler farmers mainly possess, growth or fixed? Would mindset affect the intention to adopt agricultural technology? What are the key factors that influence the farmers' intention to adopt new technology? Therefore, in order to answer these research questions, this study had 2 objectives which are: 1) to study the types of broiler farmers' mindsets, and 2) to study the influence of the broiler farmers' mindsets, performance expectancy, effort expectancy, social influence and facilitating conditions on farmers' intention to adopt the poultry farm management system. This study will help academia, entrepreneurs and farm supporters better understand the broiler farmers' internal factors and introduce the poultry farm management system to the farmers. This study applies the UTAUT model as the overall framework to study the intention to adopt the technology, i.e., the poultry farm management system, of the broiler farmers in livestock area 3, Thailand.

\section{Materials and methods}

This study is a quantitative survey research method, using questionnaire and poultry farm management systems as the research tools. The data collection process was done by interviewing farmers and fill out the questionnaire at the broiler farms and during the farmers meeting. The first step was to demonstrate the media describing the poultry farm management system when meeting with the broiler farmers. Then farmers had to try out the system before answering the questions. The questionnaire consists of 3 parts as follows:

Part 1 asks about respondents' general information such as sex, age, education, experience in broiler farming, number of houses, number of chickens raised, number of farm staff and the average farming performance per round (during the past 12 months). This part of the questionnaire uses the nominal scale.

Part 2 measures types of broiler farmers' mindsets. Questions adapted from [28] and aligned with the mindset definition offered by [24] will describe the characteristics of people who have a growth mindset. The questions in this part were designed as the scoring criteria suggested by [28]: 3 means most agree, 2 means agree, 1 means disagree and 0 means disagree.

Part 3 measures attitude on the poultry farm management system, which consisted of 5 factors: performance expectancy, effort expectancy, social influence, facilitating conditions and attitude toward using technology. The questions measuring these factors were adapted from [9]. This part was designed using the Likert Scale [29], allowing respondents to indicate their levels of agreement, which are strongly agreed, agree, moderately agree, disagree and strongly disagree.

The questionnaire's content validity test was performed by using the Index of Item-Objective Congruence (IOC). The results from individual IOC scores of the questionnaires were between 0.33 1.00. Some of the questionnaire's IOC scores failed to meet the criteria suggested by [30]; Some were too academic, ambiguous and difficult to understand. The researcher revised the questions to make them less academic and more straightforward for farmers to understand. The revised questionnaire was then pre-tested with 30 broiler farmers in Nakhon Ratchasima, Thailand. The Cronbach's $\alpha$ was calculated and analysed to check the internal consistency of the constructs and then the reliability.

The result of the individual factor Cronbach's Alpha Coefficient was between $0.526-0.831$. Some factors, i.e., performance expectancy, social influence and facilitating conditions, failed to meet the accepted value of 0.70 and up [31]. The researcher used the Principal Component Analysis (PCA) to improve the questionnaire by reducing the number of variables of a data set while preserving as much information as possible. Hence, running the PCA analysis help to eliminate some questions that were not formed well in any factors [32]. After improvement, the researcher then rechecked the Cronbach's Alpha coefficient for each factor. The resulting Cronbach's Alpha coefficients were between 0.696 - 0.836 , which fall into the acceptable range of the 0.7 cut-off value recommended by [33]. Therefore, all constructs in this study demonstrated acceptable reliability.

Regarding the suitable sample size for this study, [34] recommends the sample size is 10 - 20 per parameter. This study has 6 parameters which are mindset, Performance Expectancy (PE), Effort Expectancy (EE), Social Influence (SI), Facilitating Conditions (FC) and Attitude Toward Using Technology (ATUT). Therefore the suitable sample size for this study should be between 60 and 120 . After the questionnaire had been collected using an on-site interview, the result yielded 110 filled questionnaires.

Data analysis was performed using SPSS statistics and SPSS AMOS. The respondents' general information was analysed and described using descriptive statistics, i.e., frequency, percentage, mean and standard deviation. The first objective was analysed and tested by using the mindset range score calculated following [35]. The mindset then was divided into 4 levels, i.e., strong growth mindset, growth 
mindset, fixed mindset and strong fixed mindset, in which score range from 31.50 - 42.00, 21.01 - 31.49, $10.50-21.00$ and $0.00-10.49$, respectively [28]. The second objective was analysed and tested using structural equation modelling with maximum likelihood estimation to estimate the path coefficient and analyse the relationships between variables in the structural model based on research hypotheses. The criteria for determining the consistency of the model are the CMIN-p $(p>0.05), \mathrm{CMIN} / \mathrm{df}(<3)$, GFI $(>0.90)$ and RMSEA $(<0.08)$ [36]. When the structural equation model did not pass the model consistency checking criteria, the researchers adjusted the structural equation model by checking back with the theoretical framework, previous studies and judgement from the interview information during the data collection process [37].

\section{Results and discussion}

The sample group consisted of 110 broiler farmers in livestock area 3. The majority of respondents were male $(57.27 \%)$, age between 23 - 55 years $(78.18 \%)$, the highest education was high-school $(41.82 \%)$ and had over 8 years of experience in broiler production $(46.36 \%)$. The majority of respondents have $1-2$ broiler houses (60\%), being able to raise 20,001-100,000 chickens/crop (48.18 $\%)$, hired 1 - 2 employees (52.73\%) and had 10 - 15 baht/head on average profits (50\%).

\section{Mindset}

The results of the boiler farmers' mindset indicated the highest test score of 42, which fall into the level of a strong growth mindset. The lowest test score was 19, which falls into a fixed mindset. The average test score was 34.93 .

Table 1 The broiler farmers' mindset scores $(n=100)$

\begin{tabular}{|c|c|c|c|}
\hline Score & Frequency & Percentage & Status \\
\hline 19.00 & 1 & 0.91 & Fixed Mindset \\
\hline 23.00 & 1 & 0.91 & Growth Mindset \\
\hline 26.00 & 1 & 0.91 & Growth Mindset \\
\hline 27.00 & 1 & 0.91 & Growth Mindset \\
\hline 28.00 & 15 & 13.64 & Growth Mindset \\
\hline 29.00 & 2 & 1.82 & Growth Mindset \\
\hline 30.00 & 7 & 6.36 & Growth Mindset \\
\hline 31.00 & 6 & 5.45 & Growth Mindset \\
\hline 32.00 & 4 & 3.64 & Strong Growth Mindset \\
\hline 33.00 & 6 & 5.45 & Strong Growth Mindset \\
\hline 34.00 & 3 & 2.73 & Strong Growth Mindset \\
\hline 36.00 & 4 & 3.64 & Strong Growth Mindset \\
\hline 37.00 & 8 & 7.27 & Strong Growth Mindset \\
\hline 38.00 & 7 & 6.36 & Strong Growth Mindset \\
\hline 39.00 & 9 & 8.18 & Strong Growth Mindset \\
\hline 40.00 & 3 & 2.73 & Strong Growth Mindset \\
\hline 41.00 & 6 & 5.45 & Strong Growth Mindset \\
\hline 42.00 & 16 & 14.55 & Strong Growth Mindset \\
\hline Total & 110 & 100.00 & \\
\hline
\end{tabular}

$\overline{\mathrm{X}}=$ 34.93 S.D. $=$ 5.249 $\mathrm{Max}=42 \mathrm{Min}=19$ 
The first research objective was to study the type of boiler farmers' mindset. Tables $\mathbf{1}$ and $\mathbf{2}$ indicated that most boiler farmers in this study possess a growth mindset, and very few possess a fixed mindset.

Table 2 The broiler farmers' mindset $(n=100)$

\begin{tabular}{cccc}
\hline Score & Frequency & Percentage & Status \\
\hline $31.50-42.00$ & 75 & 68.18 & Strong Growth Mindset \\
$21.01-31.49$ & 34 & 30.91 & Growth Mindset \\
$10.50-21.00$ & 1 & 0.91 & Fixed Mindset \\
$0.00-10.49$ & 0 & 0.00 & Strong Fixed Mindset \\
Total & $\mathbf{1 1 0}$ & $\mathbf{1 0 0 . 0 0}$ & \\
\hline
\end{tabular}

\section{Attitude on the use of poultry farm management systems}

The results of the boiler farmers' attitude on the poultry farm management system showed a high level of intention to adopt the technology (ATUT) $(\overline{\mathrm{X}}=4.18)$ with a high level of performance expectancy $(\bar{X}=4.20)$, facilitating conditions $(\overline{\mathrm{X}}=4.15)$ and effort expectancy $(\overline{\mathrm{X}}=4.03)$. The lowest mean score of the boiler farmers' attitude was on social influence $(\overline{\mathrm{X}}=3.72)$.

Table 3 Farmers' attitude on the use of poultry farm management systems $(n=100)$

\begin{tabular}{lllc}
\hline \multicolumn{1}{c}{ Farmers' Attitude } & $\overline{\mathbf{X}}$ & S.D. & Status \\
\hline 1 Performance Expectancy (PE) & 4.20 & 0.71 & High \\
2. Effort Expectancy (EE) & 4.03 & 0.61 & High \\
3. Social Influence (SI) & 3.72 & 0.89 & High \\
4. Facilitating Conditions (FC) & 4.15 & 0.69 & High \\
5. Attitude toward using technology (ATUT) & 4.18 & 0.66 & High \\
\hline
\end{tabular}

When testing the relationships among the factors, the results show that most of the correlation coefficients are statistically significantly positive. The result in Table 4 indicates that most of the variables (13 pairs) have statistical significance at the level of 0.01 , and only 1 pair has a statistical significance at the level of 0.05 .

Table 4 The correlation coefficient between research variables

\begin{tabular}{lllllll}
\hline & Mindset & PE & EE & SI & FC & ATUT \\
\hline Mindset & 1.000 & & & & & \\
PE & $0.383^{* *}$ & 1.000 & & & & \\
EE & $0.415^{* *}$ & $0.633^{* *}$ & 1.000 & & & \\
SI & 0.182 & $0.323^{* *}$ & $0.270^{* *}$ & 1.000 & & \\
FC & $0.468^{* *}$ & $0.592^{* *}$ & $0.783^{* *}$ & $0.231^{*}$ & 1.000 & 1.000 \\
ATUT & $0.467^{* *}$ & $0.618^{* *}$ & $0.722^{* *}$ & $0.355^{* *}$ & $0.729^{* *}$ & \\
\hline
\end{tabular}

$* *=p<0.01, *=p<0.05$

Note: $\mathrm{PE}=$ Performance Expectancy, EE $=$ Effort Expectancy, SI = Social Influence, FC = Facilitating

Conditions and ATUT $=$ Attitude toward using technology 
The results of the structural equation analysis showed that there are 3 pairs of significant pairs of $0.001(* * * p<0.001)$ which are 1) PE $\leftarrow$ Mindset 2) ATUT $\leftarrow$ EE and 3) ATUT $\leftarrow$ FC the 1 pair of significant variable $0.01(* * p<0.01)$ is ATUT $\leftarrow \mathrm{PE}$, the 1 pair of significant variable $0.05(* p<0.05)$ The pair is ATUT $\leftarrow$ SI and 1 pair that is not statistically significant is the ATUT $\leftarrow$ Mindset as shown in Table 5.

Table 5 The standardized regression weights estimation results.

\begin{tabular}{lccccc}
\hline Path & Estimate & S.E. & t-Value & $\boldsymbol{p}$-Value & Remarks \\
\hline PE $\leftarrow$ Mindset & 0.052 & 0.012 & 4.332 & $* * *$ & Significant \\
ATUT $\leftarrow$ PE & 0.146 & 0.057 & 2.555 & $0.011^{* *}$ & Significant \\
ATUT $\leftarrow$ EE & 0.295 & 0.061 & 4.820 & $* * *$ & Significant \\
ATUT $\leftarrow$ SI & 0.097 & 0.042 & 2.300 & $0.021^{*}$ & Significant \\
ATUT $\leftarrow$ FC & 0.320 & 0.054 & 5.880 & $* * *$ & Significant \\
ATUT $\leftarrow$ Mindset & 0.014 & 0.008 & 1.768 & 0.077 & Not Significant \\
\hline
\end{tabular}

$* * * p<0.001, * *=p<0.01, *=p<0.05$

From result analysis of the coefficient showed one path with no statistical significance. Therefore, the structural equation model's first structural adjustment was performed by removing the statistically insignificant path from the full correlation model. The results of structural equation analysis after model adjustment is shown in Table 6.

Table 6 The estimated results of standardised regression weights after model adjustment.

\begin{tabular}{lccccl}
\hline Path & Estimate & SE. & t-Value & $\boldsymbol{p}$-Value & Remarks \\
\hline PE $\leftarrow$ Mindset & 0.052 & 0.012 & 4.332 & $* * *$ & Significant \\
ATUT $\leftarrow$ PE & 0.159 & 0.053 & 2.988 & $0.003^{* *}$ & Significant \\
ATUT $\leftarrow$ EE & 0.302 & 0.062 & 4.862 & $* * *$ & Significant \\
ATUT $\leftarrow$ SI & 0.101 & 0.043 & 2.360 & $0.018^{*}$ & Significant \\
ATUT $\leftarrow$ FC & 0.355 & 0.055 & 6.439 & $* * *$ & Significant \\
\hline
\end{tabular}

$* * * p<0.001, * *=p<0.01, *=p<0.05$

The result of model consistency showed Chi-square 192.044, Chi-square/df 19.204, df 10, p 0.000, the GFI 0.635 and RMSEA 0.409 , did not pass the criteria by [36]. The researcher adjusted the structural equation model following the recommendation [37], and the result showed in Figure 1. 


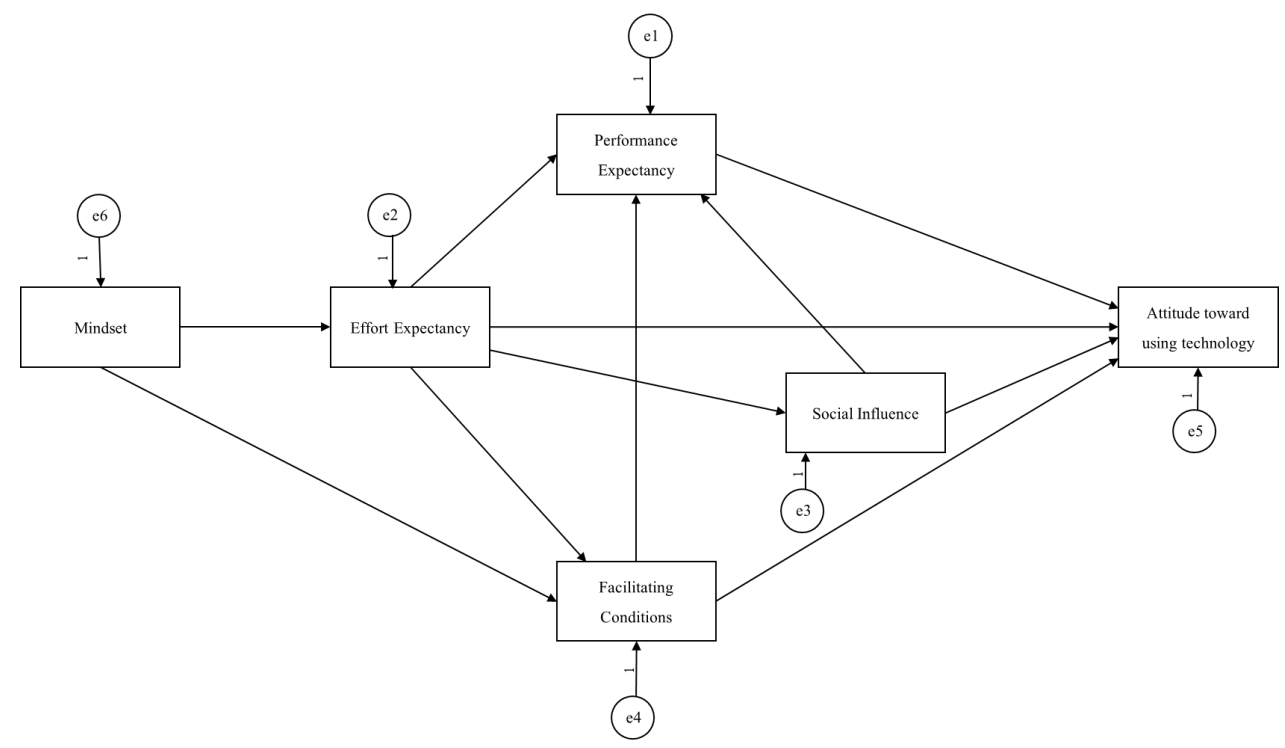

Figure 1 Alternative model.

The results of the structural equation analysis showed that there are 4 pairs with a statistical significance level at $0.001(* * * p<0.001)$, which are 1) $\mathrm{EE} \leftarrow$ Mindset, 2) $\mathrm{FC} \leftarrow \mathrm{EE}, 3) \mathrm{PE} \leftarrow \mathrm{EE}$ and 4) ATUT $\leftarrow$ FC. There are 2 pairs with a statistical significance level at $0.0010 .01(* * * p<0.01)$, which are 1) SI $\leftarrow$ EE and 2) FC $\leftarrow$ Mindset. Furthermore, there are 5 pairs with a statistical significance level at $0.0010 .05(* * * p<0.05)$; which are 1) ATUT $\leftarrow \mathrm{EE}, 2)$ ATUT $\leftarrow$ PE, 3) ATUT $\leftarrow$ SI, 4) PE $\leftarrow$ SI and, 5) $\mathrm{PE} \leftarrow \mathrm{FC}$, as shown in Table 7.

Table 7 The estimation of standardised regression weights after the $2^{\text {nd }}$ model adjustment.

\begin{tabular}{lccccc}
\hline Path & Estimate & SE. & t-Value & $\boldsymbol{p}$-Value & Remarks \\
\hline E.E. $\leftarrow$ Mindset & 0.048 & 0.010 & 4.759 & $* * *$ & Significant \\
F.C. $\leftarrow$ E.E. & 0.801 & 0.071 & 11.235 & $* * *$ & Significant \\
F.C. $\leftarrow$ Mindset & 0.023 & 0.008 & 2.734 & $0.006^{* *}$ & Significant \\
SI $\leftarrow$ EE & 0.391 & 0.134 & 2.922 & $0.003^{* *}$ & Significant \\
PE $\leftarrow$ EE & 0.469 & 0.135 & 3.464 & $* * *$ & Significant \\
PE $\leftarrow$ SI & 0.127 & 0.059 & 2.149 & $0.032^{*}$ & Significant \\
PE $\leftarrow$ FC & 0.249 & 0.118 & 2.100 & $0.036^{*}$ & Significant \\
ATUT $\leftarrow$ PE & 0.159 & 0.072 & 2.220 & $0.026^{*}$ & Significant \\
ATUT $\leftarrow$ EE & 0.302 & 0.107 & 2.827 & $0.005^{*}$ & Significant \\
ATUT $\leftarrow$ SI & 0.101 & 0.045 & 2.226 & $0.026^{*}$ & Significant \\
ATUT $\leftarrow$ FC & 0.355 & 0.090 & 3.925 & $* * *$ & Significant \\
\hline
\end{tabular}

$* * * p<0.001, * *=p<0.01, *=p<0.05$

Figure 2.

The adjusted path analysis results between independent variables and dependent variables display in 


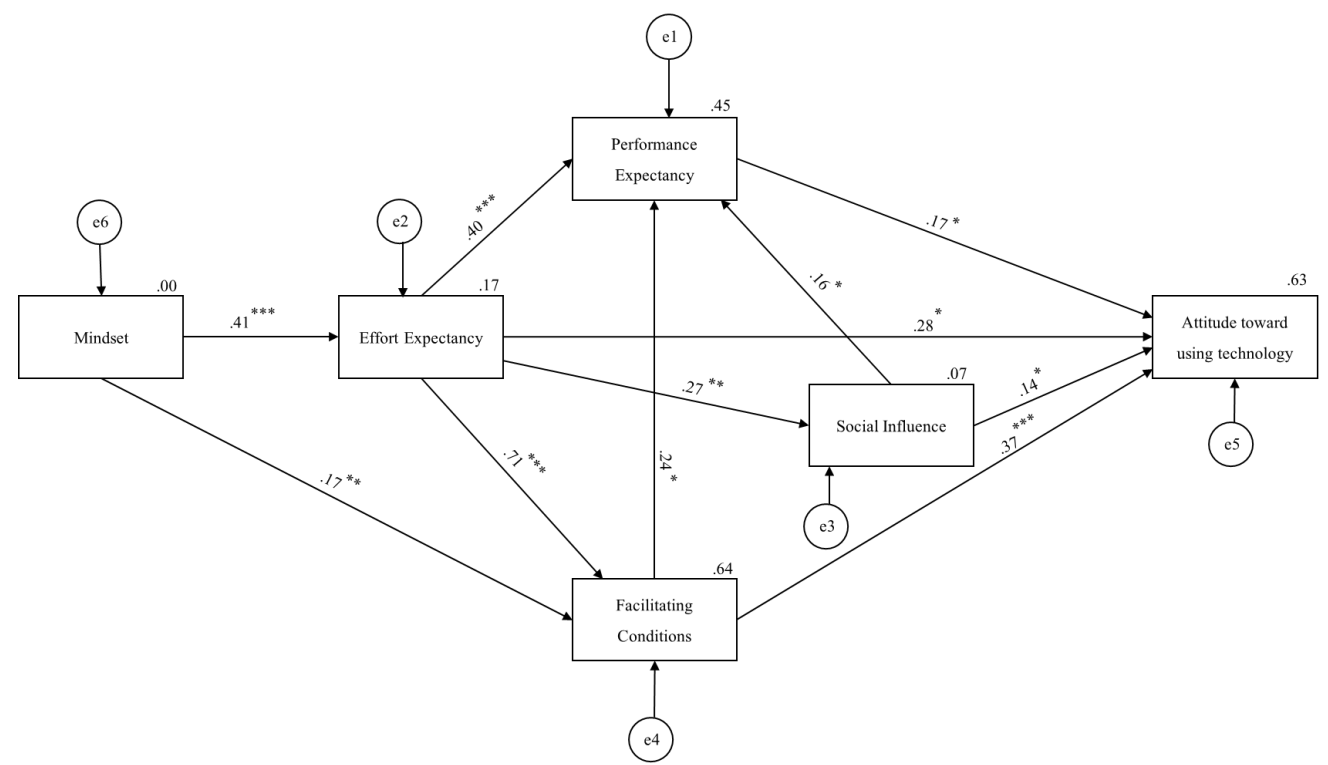

Figure 2 The adjusted path model for the causal relationship

Note: Chi-square $=4.925$, Chi-square $/ \mathrm{df}=1.231, \mathrm{df}=4, p=0.295, \mathrm{GFI}=0.985$ and $\mathrm{RMSEA}=0.046$

The result of model consistency showed Chi-square 4.925 , Chi-square/df 1.231 , df $4, p 0.295$, the GFI 0.985 and RMSEA 0.046 , pass the criteria by [36]. The direct effect, indirect effect and total effect of the model shown in Table 8.

Table 8 The results of the direct influence, indirect influence and the total influence of factors.

\begin{tabular}{|c|c|c|c|}
\hline & Direct effect & Indirect effect & Total effect \\
\hline Mindset $\rightarrow$ PE & 0.00 & 0.29 & 0.29 \\
\hline Mindset $\rightarrow$ EE & 0.41 & 0.00 & 0.41 \\
\hline Mindset $\rightarrow$ SI & 0.00 & 0.11 & 0.11 \\
\hline Mindset $\rightarrow$ FC & 0.17 & 0.29 & 0.46 \\
\hline Mindset $\rightarrow$ ATUT & 0.00 & 0.24 & 0.24 \\
\hline $\mathrm{PE} \rightarrow \mathrm{EE}$ & 0.00 & 0.00 & 0.00 \\
\hline $\mathrm{PE} \rightarrow \mathrm{SI}$ & 0.00 & 0.00 & 0.00 \\
\hline $\mathrm{PE} \rightarrow \mathrm{FC}$ & 0.00 & 0.00 & 0.00 \\
\hline $\mathrm{PE} \rightarrow \mathrm{ATUT}$ & 0.17 & 0.00 & 0.17 \\
\hline $\mathrm{EE} \rightarrow \mathrm{PE}$ & 0.40 & 0.21 & 0.61 \\
\hline $\mathrm{EE} \rightarrow \mathrm{SI}$ & 0.00 & 0.00 & 0.00 \\
\hline $\mathrm{EE} \rightarrow \mathrm{FC}$ & 0.71 & 0.00 & 0.71 \\
\hline $\mathrm{EE} \rightarrow \mathrm{ATUT}$ & 0.28 & 0.40 & 0.68 \\
\hline $\mathrm{SI} \rightarrow \mathrm{PE}$ & 0.16 & 0.00 & 0.16 \\
\hline $\mathrm{SI} \rightarrow \mathrm{EE}$ & 0.00 & 0.00 & 0.00 \\
\hline $\mathrm{SI} \rightarrow \mathrm{FC}$ & 0.00 & 0.00 & 0.00 \\
\hline $\mathrm{SI} \rightarrow$ ATUT & 0.14 & 0.03 & 0.17 \\
\hline $\mathrm{FC} \rightarrow \mathrm{PE}$ & 0.24 & 0.00 & 0.24 \\
\hline $\mathrm{FC} \rightarrow \mathrm{EE}$ & 0.00 & 0.00 & 0.00 \\
\hline $\mathrm{FC} \rightarrow \mathrm{SI}$ & 0.00 & 0.00 & 0.00 \\
\hline $\mathrm{FC} \rightarrow \mathrm{ATUT}$ & 0.37 & 0.04 & 0.41 \\
\hline
\end{tabular}

Note: $\mathrm{PE}=$ Performance Expectancy, EE = Effort Expectancy, SI = Social Influence, FC = Facilitating Conditions and ATUT $=$ Attitude Toward Using Technology 
The second research objective was to study the influence of the broiler farmers' mindsets, performance expectancy, effort expectancy, social influence, and facilitating conditions on the attitude (intention) to adopt the poultry farm management systems. The results indicated that all of the factors influenced farmers' intention to adopt poultry farm management systems. However, the most influential factor was effort expectancy (0.68), followed by the facilitating conditions (0.41). Mindset plays a significant role in effort expectancy $(0.41)$.

\section{Conclusions}

Thai broiler farmers face risk in competition because of lack of technology compared with major exporting countries of the world; therefore, there is a need to introduce new technology to farmers to increase their competitiveness. However, many concerns have been expressed through various means regarding the challenge of doing that. The most concern issue was the farmers' resistance to investing in products or services they cannot use. The public view that farmers are fixed and afraid of technology. However, this study aims to uncover the type of farmers' mindset and the factors that would affect farmers' intention to adopt a poultry farm management system.

The results indicated that almost all farmers in the study possess a growth mindset. This result does not align with previous public assumptions. The reason would be that this group of broiler farmers are the contract farms of the big corporate. In the structure of the broiler industry, most farmers are subjected to contract farming with large companies. The large companies have a department responsible for the care and promotion that will visit and advise to improve the farming for the broiler farmers. Also, broiler farming must be certified by the Department of Livestock Development and adhere to the periodic assessment of farm standards. They must keep updated with new technology and information to conform to the buyers' requirements, i.e., GAP (Good Agriculture Practices). [38-40] shows that broiler farmers are the top 5 of all types of farmers who get the GAP certificate. Considering that most of these farmers have more than 8 years of experience operating broiler farms, they have been through many economic, social and regulatory changes. These characters, process and compliance, could cause farmers to improve themselves and their farms constantly. In turn, it makes the broiler farmers in this study exhibit a growth mindset. According to [24], they exhibit the characters that farmers with this mindset believe in their nature and character that intelligence can be developed. This growth mindset gives people a desire to learn and resulting in a tendency to like a challenge. When confronted with obstacles, these farmers will continue to strive despite failures. They see effort as a means of expertise and learn from the reviews.

The UTAUT factors such as performance expectancy, effort expectancy, social influence and facilitating condition influenced broiler farmers' intention to adopt poultry farm management systems. The most influential factor was effort expectancy, followed by the facilitating conditions. As defined in [9] adopted as a model in the study, the effort expectancy is the users' feeling of difficulty with the technology. From the results of this study, it was found that effort expectancy has the most influence on adopting the poultry farm management system. The result is in line with previous studies on the adoption of information technology among farmers, such as [41] finding that increasing yield and effort expectations (effort expectancy) significantly influence the use of information technology

This study showed that mindset has an indirect influence on the intention to adopt the poultry farm management system through effort expectancy and facilitating conditions. Considering the explanation of [19] regarding mindset, people with growth and fixed mindsets are different in effort perception. People with a growth mindset tend to focus on efforts and see effort as a path to expertise. Therefore, these people will focus on learning, experimenting and self-development. In contrast, people with a fixed mindset see efforts as a negative thing. They believe that intelligence is something that human has born with, and it is irreversible. Their resulted behaviour would be that they are not open to learning new things.

The implication from this research result for entrepreneurs and other organisations in developing technology for farmers is that they need to design and develop technology that farmers can use easily with less effort in learning new things, not to invest in buying tools, e.g., expensive smartphone or invest in building their infrastructure. It would be even better to design the technology that can be used in conjunction with what farmers already have or experience. These will likely have a chance of success in bringing technology into this group of farmers. This result is in line with [7] that addresses the challenge of agricultural technology companies to develop farmers-friendly products/services. Farmer-friendly solutions must be affordable and easy to use, as one of the main reasons the technology's non-adoption is the result of farmers' opposition to investing. In products/services that they cannot use. The governments or farm promotion department from big companies should focus on providing training or skill-developing 
tools to help develop farmers' growth mindset. This capacity-building process will help farmers expand their view on adopting new technology, tools and methods in their farm operation. Furthermore, this will lead to the competitiveness of the farmers and farm's products.

\section{Acknowledgement}

This research had received financial support from external grants and scholarships for graduate students (OROG) from the Suranaree University of Technology.

\section{References}

[1] Office of the National Broadcasting and Telecommunications Commission, Available at: http://www.nbtc.go.th, accessed July 2018.

[2] T Goodwin. Digital darwinism: Survival of the fittest in the age of business disruption. Kogan Page, New York, 2018, p. 11-2.

[3] P Booasang. Digital Transformation (in Thai), Available at: https://www.scbeic.com/th/detail/product/4327, accessed July 2018.

[4] R Agarwal, S Chandrasekaran and M Sridhar. Imagining construction's digital future, Available at: https://www.mckinsey.com/industries/capital-projects-and-infrastructure/our-insights/imaginingconstructions-digital-future, accessed July 2018.

[5] W Petchseechoung. Frozen \& processed chicken industry, Available at: https://www.krungsri.com/ bank/getmedia/547be15f-6d5d-44c3-ace7-996f3d03e4dc/IO_Chicken_2016_EN.aspx, accessed November 2017.

[6] W Petchseechoung. Frozen \& processed chicken industry, Available at: https://www.krungsri.com/ bank/getmedia/81639011-fd0b-4e89-8a38-64402b37ccce/IO_Chicken_171019_EN_EX.aspx, accessed July 2018.

[7] G Bucci, D Bentivoglio and A Finco. Factors affecting ICT adoption in agriculture: A case study in Italy. Qual. Access Success 2019; 20, 122-9.

[8] I Ajzen. The theory of planned behavior. In: PAM Van Lange, AW Kruglanski and ET Higgins (Eds.). Handbook of theories of social psychology. Sage, London, 2012, p. 438-57.

[9] V Venkatesh, MG Morris, GB Davis and FD Davis. User acceptance of information technology: Toward a unified view. MIS Q. 2003; 27, 425-78.

[10] M Sharifzadeh, GH Zamani, D Khalili and E Karami. Agricultural climate information use: An application of the planned behaviour theory. J. Agr. Sci. Tech. 2012; 14, 479-92.

[11] I Artikov, SJ Hoffman, GD Lynne, LM PytlikZillig, Q Hu, A Tomkins, KG Hubbard, MJ Hayes and WJ Waltman. Understanding the influence of climate forecasts on farmer decisions as planned behavior. J. Appl. Meteorol. Climatol. 2006; 45, 1202-14.

[12] M Ali, N Man, FM Muharam and SZ Omar. Factors influencing behavioral intention of farmers to use ICTs for agricultural risk management in Malaysia. Pakistan J. Agr. Res. 2020; 33, 295-302.

[13] P Watcharaanantapong, RK Roberts, DM Lambert, JA Larson, M Velandia, BC English, RM Rejesus and C Wang. Timing of precision agriculture technology adoption in U.S. cotton production. Precis. Agr. 2014; 15, 427-46.

[14] S Zheng, Z Wang and CJ Wachenheim. Technology adoption among farmers in Jilin Province, China. China Agr. Econ. Rev. 2019; 11, 206-16.

[15] J Lee, K Kim, H Shin and J Hwang. Acceptance factors of appropriate technology: Case of water purification systems in Binh Dinh, Vietnam. Sustainability 2018; 10, 2255.

[16] M Michels, V Bonke and M Oliver. Understanding the adoption of crop protection smartphone apps: An application of the unified theory of acceptance and use of technology. Diskussionsbeitrag $2019 ; 2019,1905$.

[17] N Nejadrezaei, MS Allahyari, M Sadeghzadeh, A Michailidis and HE Bilali. Factors affecting adoption of pressurised irrigation technology among olive farmers in Northern Iran. Appl. Water Sci. 2018; 8, 190.

[18] J Molina-Maturano, N Verhulst, J Tur-Cardona, DT Güereña, A Gardeazábal-Monsalve, B Govaerts and S Speelman. Understanding smallholder farmers' intention to adopt agricultural apps: The role of mastery approach and innovation hubs in Mexico. Agronomy 2021; 11, 194.

[19] J Krümpel. 2019, Factors influencing the use of mobile applications by farmers for data and information management. M. Sc. Thesis. Wageningen University \& Research, Wageningen, Netherlands. 
[20] S Bates, B Brunsman and P Crozier. Available at: https://assets.kpmg/content/dam/kpmg/xx/pdf/ 2019/03/market-speed-it-operating-models-in-the-age-of-the-connected-enterprise.pdf, accessed April 2021.

[21] GC Kane, D Palmer, AN Phiilps, D Kinron and N Buckley. Available at: https:/www2.deloitte.com /us/en/insights/focus/digital-maturity/coming-of-age-digitally-learning-leadership-legacy.html, accessed April 2021.

[22] A Derler. Available at: https://www.researchgate.net/publication/341219768, accessed April 2021.

[23] CS Dweck and DC Molden. Mindsets: Their impact on competence motivation and acquisition. In: AJ Elliot, CS Dweck and DS Yeager (Eds.). Handbook of competence and motivation: Theory and application. $2^{\text {nd }}$ ed. Guilford Press, New York, 2017, p. 135-54.

[24] CS Dweck. Mindset: The new psychology of success. Ballantine Books, New York, 2008, p. 3-11.

[25] MC Murphy and CS Dweck. Mindsets shape consumer behavior. J. Consum. Psychol. 2015; 26, 127-36.

[26] MA Martinez. 2018, Mindset as it relates to implementation of mobile devices for instruction. $\mathrm{Ph}$. D. Dissertation. The University of Texas at Arlington, Texas, United States.

[27] KL Stewart. 2018, The role of growth mindset and efficacy in teachers as change agents. Ed. D. Dissertation. Saint Mary's College of California, Ann Arbor, United States.

[28] E Diehl, Available at: http://www.classroom20.com/forum/topics/motivating-students-with, accessed August 2018.

[29] R Likert. The method of constructing an attitude scale. In: GM Maranell (Ed.). Scaling: A sourcebook for behavioral scientists. Aldine Transaction, New Jersey, United States, 2007, p. 23343.

[30] B Srisatidnarakul. Development and validation of research instruments: Psychometric properties (in Thai). Chulalongkorn University Printing House, Bangkok, Thailand, 2012.

[31] S Prasitratthasin. Social science research methodology (in Thai). Fueang Fa Printing, Bangkok, Thailand, 2003.

[32] N Songsrirote, Available at: http://www.nitiphong.com/paper_pdf/phd/FactorAnalysis_concept.pdf, accessed August 2018.

[33] JC Nunnally. Psychometric theory. Vol II. McGraw-Hill, New York, 1978.

[34] JF Hair, WC Black, BJ Babin and RE Anderson. Multivariate data analysis. Pearson Prentice Hall, New Jersey, United States, 2010.

[35] M Bunnag. Statistical analysis for decision making (in Thai). Chulalongkorn University, Bangkok, Thailand, 1994.

[36] T Silpcharu. Research and data analysis by SPSS and AMOS (in Thai). Business R and D, Bangkok, Thailand, 2012.

[37] R Songsraboon. Structural equation modelling for prediction (in Thai). Silpakorn Univ. J. 2018; 38, 185-205.

[38] Bureau of Livestock Standards and Certifaication, Available at: https:/certify.dld.go.th/certify/ index.php/th/2016-05-01-14-50-24, accessed May 2020.

[39] Plant Standard and Certification Division, Available at: http://gap.doa.go.th, accessed May 2020.

[40] Fisheries Commodity Standard System and Traceability Division, Available at: http://thacert. fisheries. go.th/wscert/site/certificate_list.jsp, accessed May 2020.

[41] DW Kahenya, M Sakawa and M Iravo. Assessing use of information communication technologies among agricultural extension workers in Kenya using modified UTAUT model. Int. J. Sci. Basic Appl. Res. 2014; 16, 11-22. 